\title{
Microsomal epoxide hydrolase, glutathione S-transferase P1, traffic and childhood asthma
}

\author{
Muhammad T Salam, Pi-Chu Lin, Edward L Avol, W James Gauderman, Frank D Gilliland
}

Thorax 2007;62:1050-1057. doi: 10.1136/thx.2007.080127

See end of article for authors' affiliations

Correspondence to:

Dr Frank D Gilliland,

Department of Preventive Medicine, USC Keck School of Medicine, 1540 Alcazar Street, CHP' 236, Los

Angeles California 90033,

USA; gillilan@usc.edu

Received 21 February 2007 Accepted 2 July 2007
Background: Microsomal epoxide hydrolase (EPHX1) metabolises xenobiotics including polyaromatic hydrocarbons (PAHs). Functional variants at this locus have been associated with respiratory diseases. The effects of EPHX1 variants may depend upon exposures from tobacco smoke and traffic emissions that contain PAHs as well as variants in other enzymes in the PAH metabolic pathway such as glutathione S-transferase (GST) genes. A study was undertaken to investigate associations of variants in EPHXI, GSTM1, GSTP1 and GST1 with asthma and the relationships between asthma, EPHXI metabolic phenotypes and exposure to sources of PAHs. Methods: Odds ratios (ORs) and $95 \%$ confidence intervals (Cls) were computed to estimate the associations of genetic variants and exposures with asthma phenotypes using data from 3124 children from the Children's Health Study.

Results: High EPHXI activity was associated with an increased risk for lifetime asthma (OR 1.51, 95\% Cl 1.14 to 1.98) which varied by GSTP1 lle105Val genotype and by residential proximity to major roads ( $p$ for interaction $=0.006$ and 0.03 , respectively). Among children with GSTP1 $105 \mathrm{Val} / \mathrm{Val}$ genotype, those who had high EPHX1 phenotype had a fourfold $(95 \% \mathrm{Cl} 1.97$ to 8.16$)$ increased risk of lifetime asthma than children with low/intermediate EPHXI phenotype. Among children living within 75 metres of a major road, those with high EPHX1 activity had a 3.2 -fold ( $95 \% \mathrm{Cl} 1.75$ to 6.00) higher lifetime asthma risk than those with low/intermediate activity. The results were similar for current, early persistent and late onset asthma. Children with high EPHX1 phenotype, GSTP1 Val/Val genotype who lived $<75$ metres from a major road were at the highest asthma risk.

Conclusion: EPHX1 and GSTP1 variants contribute to the occurrence of childhood asthma and increase asthma susceptibility to exposures from major roads.
A sthma is the most common chronic disease in children and remains a significant public health concern. An emerging body of evidence suggests that traffic-related pollution near home increases the risk of asthma ${ }^{12}$ and reduces lung growth ${ }^{3}$ in children. In addition, in utero and second hand exposures to smoking have been associated with an increased risk of asthma in children. ${ }^{4}$ Incomplete combustion of constituents of tobacco and fossil fuels generates complex mixtures that include high levels of polyaromatic hydrocarbons (PAHs). ${ }^{12}{ }^{4} \mathrm{PAH}$ exposure, which results in oxidative stress, has been associated with asthma and wheeze. ${ }^{6-8}$

Enzymes that metabolise xenobiotics appear to play a role in the pathogenesis of asthma. ${ }^{5}$ Although epidemiological studies have examined the associations between a spectrum of genes encoding enzymes involved in xenobiotic metabolism, such as glutathione S-transferase (GST) Ml, Pl and $\mathrm{Tl},{ }^{9-15}$ the contribution of another enzyme encoded by the microsomal epoxide hydrolase (EPHX1) gene to childhood asthma has not been extensively investigated.

The potential role of EPHXI and GSTs in asthma stems from the function of the encoded enzyme in several important xenobiotic metabolic pathways and the subsequent oxidant stress-mediated tissue damage that may contribute to the pathogenesis of asthma (fig 1). EPHXl is involved in the detoxification of reactive epoxides from metabolically activated PAHs to generate trans-dihydrodiols, whereas GSTs detoxify PAHs through formation of glutathione conjugates. In one metabolic pathway trans-dihydrodiols are metabolised to semiquinones, which may produce oxidative stress through catalytic generation of reactive oxygen species (ROS). ${ }^{16}$

Two single nucleotide polymorphisms (SNPs) in the EPHXl gene that affect enzyme activities have been studied extensively. In an in vitro study, a tyrosine to histidine substitution at codon 113 in exon 3 (ie, Tyrl13His) reduced enzyme activity by $\geqslant 50 \%$ whereas a histidine to arginine substitution at codon 139 in exon 4 (ie, His139Arg) increased enzyme activity by $\geqslant 25 \%{ }^{17}$ These variant alleles, however, exerted modest effects on EPHXI enzyme activity in in vivo studies. ${ }^{18}$ Based on the differences in EPHXl activity by these two SNPs, EPHXI metabolic phenotypes have been formulated using genotypic combinations. ${ }^{19}{ }^{20}$ Among GSTs, homozygous deletion of GSTMI and GSTTl genes results in complete absence of enzyme activity, ${ }^{21}{ }^{22}$ whereas an isoleucine to valine substitution at codon 105 (ie, Ile105Val) in exon 5 of the GSTP1 gene affects enzyme activity in PAH metabolism and results in increased oxidant stress. ${ }^{823}$

Because EPHXI and GSTs affect metabolism of potentially toxic xenobiotics such as PAHs, it is likely that the risk of asthma in children from these sources of PAH exposure may depend on a combination of EPHXl and GST genotypes. Although an earlier study found joint effects of EPHXI and GSTP1 on chronic obstructive pulmonary disease, ${ }^{24}$ the joint effects of these genes and exposures to important sources of PAHs (smoking and traffic emissions) on the occurrence of childhood asthma is largely unknown.

We have undertaken a study to test the following three hypotheses:

Abbreviations: AKR1 aldo-keto reductase family 1, ; EPHX1, epoxide hydrolase; GST, glutathione S-transferase; $\mathrm{PAH}$, polyaromatic hydrocarbon; ROS, reactive oxygen species; SNP, single nucleotide polymorphism 
PAH (eg, naphthalene)

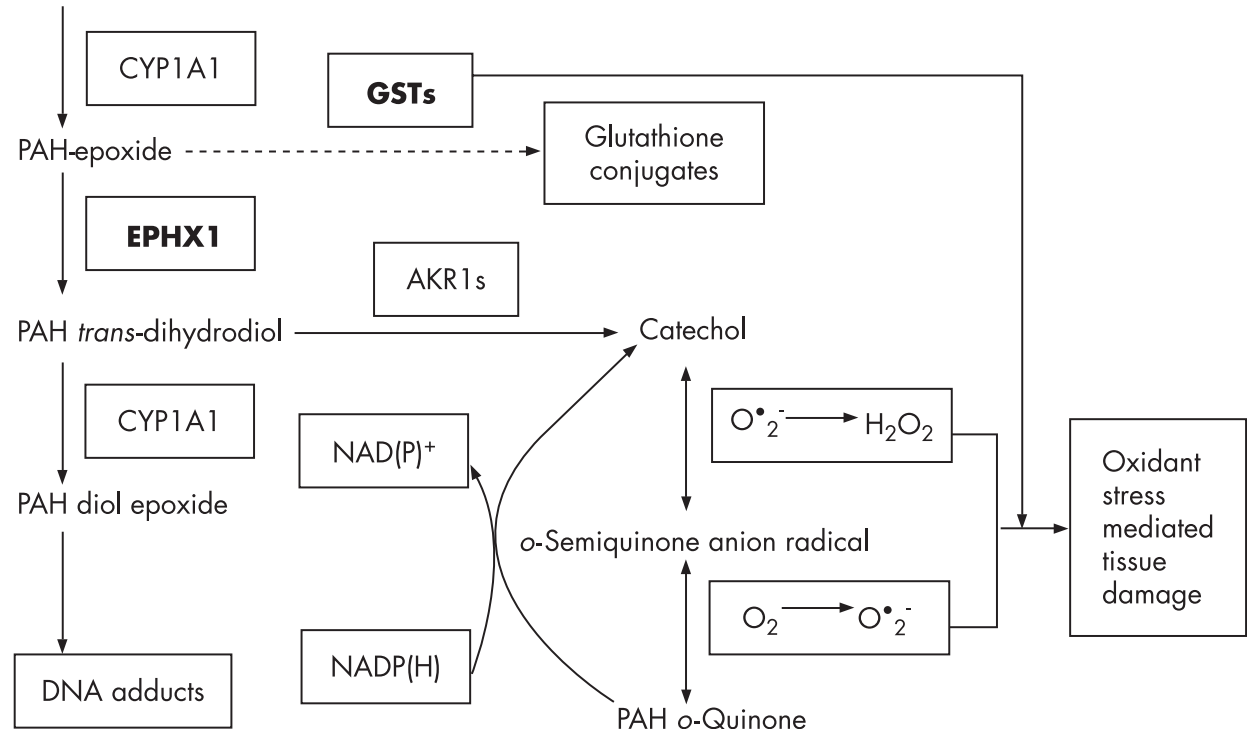

Figure 1 Genes involved in metabolism of polyaromatic hydrocarbons (PAHs) and putative mechanism of asthma occurrence from oxidant stress mediated tissue damage. Genes with functional polymorphisms that are studied are shown in bold. Glutathione S-transferase (GST) P1 105Val/Val genotype increases oxidant stress mediated tissue damage and reduces catalytic activity of the enzyme (broken arrow), resulting in an increased PAH-epoxide pool. Subsequently, higher catalytic efficiency of epoxide hydrolase (EPHX1) variants (ie, high EPHX1 phenotype) increases the formation of trans dihydrodiol which subsequently undergoes redox cycling leading to the formation of reactive oxygen species. AKR1, aldo-keto reductase 1; NADP, nicotinamide adenine dinucleotide phosphate; CYPIAl, cytochrome $\mathrm{PlAl} ; \mathrm{H}_{2} \mathrm{O}_{2}$, hydrogen peroxide.
- EPHXl polymorphisms, phenotypes and diplotypes are associated with asthma.

- Genetic variants in GSTP1, GSTMl and GSTT1 modify the relationship of EPHXI phenotypes with asthma.

- Associations between EPHXI phenotype and asthma depend upon exposure to smoking (in utero and second hand smoke) and residential proximity to major roads.

\section{METHODS}

\section{Study design and subjects}

Study subjects were drawn from the larger Children's Health Study population which has been described previously. ${ }^{25}{ }^{26}$ The Institutional Review Board of the University of Southern California approved the study. The present analysis included 3124 non-Hispanic and Hispanic white children with known asthma status who attended schools in 12 southern California communities. Children were 4 th, 7 th and 10th grade students of average age 10, 13 and 16 years, respectively, and were enrolled during 1993-6. Details of the study design and subjects are given in the online supplement available at http:// thorax.bmj.com/supplemental.

\section{Genotyping}

Details concerning buccal sample collection, processing, primer and probe information (table El) and genotyping methods are given in the online supplement available at http://thorax.bmj.com/supplemental. The genotyping for the GSTP1 Ilel05Val and EPHXI Tyrl13His and His139Arg was performed using the TaqMan Allelic Discrimination (AD) assay. Genotyping for the GSTT1 (null/present) and GSTMl (null/present) genotypes were determined by real-time PCR.

\section{Exposure assessment}

Distance to the nearest major road (in metres) from each child's home was calculated with the ArcGIS 9.1 NEAR function (Redlands, California, USA). We defined road size using the TeleAtlas Geographic Data Technology (Boston, Massachusetts, USA) feature class codes (FCC) and labelled roads with an FCC code in groups $\mathrm{Al}, \mathrm{A} 2$ and $\mathrm{A} 3$ as major roads. These codes represented primary highways with limited access, primary roads without limited access, and secondary and connecting roads, respectively. Lower classifications (A4-A7) covered local roads, neighbourhood road, rural roads, vehicular trails, roads with special characteristics and other thoroughfares. Information was collected on maternal smoking during pregnancy, lifetime history of second hand smoke exposure and number of smokers ( $0,1,2$ or more) at home upon cohort entry using a standardised questionnaire..$^{25}$

\section{Determination of EPHX 1 phenotypes and diplotype}

We used methods described by Benhamou ${ }^{19}$ for determining the EPHXI phenotypes (table E2 in online supplement available at http://thorax.bmj.com/supplemental). The EPHXl diplotype frequencies in non-Hispanic and Hispanic white children were imputed separately using the SAS macro code written by Dr Daniel Stram (available at http://www-rcf.usc.edu/ stram/ tagSNPs.html). This imputation technique uses the partitionligation expectation-maximum algorithm and provides the maximum likelihood estimates of the haplotype frequencies assuming Hardy-Weinberg equilibrium. ${ }^{27}$ Haplotype frequency data imputed for each racial/ethnic group were used for analysis in the overall sample.

\section{Outcome assessment}

We defined lifetime history of asthma based on parental report of physician-diagnosed asthma at enrolment to the Children's Health Study. A total of 476 children (15.5\%) had a diagnosis of asthma. Based on the age at asthma onset and symptom persistence, we divided lifetime asthma into three subgroups: early transient, early persistent and late onset as described by Martinez et al. ${ }^{28}$ Early transient asthma cases $(n=60)$ were diagnosed before the age of 3 years but had no asthma symptoms or medication use after first grade. Early persistent asthma was defined as a diagnosis before the age of 3 years and at least one episode of wheeze or asthma medication use after starting first grade $(n=175)$. Children diagnosed with asthma after the age of 3 years were classified as having late onset asthma $(\mathrm{n}=241)$. Current asthma was defined based on parental response to the question: "Which best describes the child's current level of asthma symptoms?" We defined current asthma based on parental response that described asthma symptoms in the previous 12 months which may have required asthma medication on an occasional or regular basis and/or hospital admission. 


\section{Power calculation}

The study had $80 \%$ power to detect ORs of $0.70,1.47$ and 1.37 for EPHX1 Tyrl13His, His139Arg and GSTP1 Ilel05Val genotypes for early persistent asthma (asthma phenotype with the lowest number of cases), respectively (table E3 in the online supplement available at http://thorax.bmj.com/supplemental). Because other asthma phenotypes had higher sample sizes, less strong ORs for these asthma phenotypes could be detected with $80 \%$ power. For testing the interactions, the study had $>80 \%$ power to detect ORs of 1.62 and 2.30 for the modifying effects of GSTP1 Ilel05Val genotype and residential distance $<75$ metres from a major road, respectively. For the joint effects of EPHXl phenotype, GSTP1 Ilel05Val genotype and residential location $<75$ metres from a major road, the study had $80 \%$ power to detect an OR of 7.2 (table E4 in the online supplement available at http://thorax.bmj.com/supplemental).

\section{Statistical analysis}

We tested our hypotheses in the combined Hispanic and nonHispanic white population as well as separately within these two racial/ethnic groups. Because the associations between EPHXl and asthma were similar by racial/ethnic group (no effect modification by race/ethnicity), the results are presented for the combined population. Because early and late onset asthma may have different pathobiologies, the results were presented by asthma phenotype. To assess the relationship between asthma and EPHXl (genotypes, phenotypes and diplotypes) and GSTM1, GSTP1 and GSTP1 Ilel05Val genotypes, logistic regression models were used to compute odds ratios (ORs) and 95\% confidence intervals (CI). Models were adjusted for age, sex, race/ethnicity, in utero exposure to smoking, number of smokers at home, parental history of asthma, parent/guardian education, health insurance coverage and community of residence. Adjusting for the atopic status of the child (based on a parental report of allergy and/or hay fever) did not change the ORs by 5\% and EPHXI phenotypes were not associated with atopy $(p=0.20)$. We therefore did not include the atopic status of the child in the models. Because the EPHXI 113His and 139His alleles are associated with low EPHXI activity, we computed the ORs for carrying one copy of 113Tyr-139His (high-low), 113His-139Arg (low-high) and 113Tyr-139Arg (high-high) diplotypes compared with those carrying two copies of the 113His-139His (low-low) diplotype using an additive genetic model.

The relationship between EPHXl phenotypes and asthma in children who inherited specific functional polymorphisms in GSTMI, GSTPI and GSTT1 was studied. We also examined whether residential location near major roads, in utero exposure to maternal smoking, exposure to second hand smoke, atopic status of the child, parental history of asthma, race/ethnicity and sex modified any associations between EPHXl and asthma using likelihood ratio tests. Because children who had intermediate EPHXl activity were not at increased risk of asthma, the low and intermediate EPHXl

\begin{tabular}{|c|c|c|c|c|c|}
\hline & \multicolumn{2}{|c|}{ No asthma } & \multicolumn{2}{|c|}{ Lifetime asthma } & \multirow[b]{2}{*}{$\mathrm{p}$ Valueł } \\
\hline & $\mathrm{N}+$ & (\%) & $\overline{\mathrm{N}}$ & (\%) & \\
\hline \multicolumn{6}{|l|}{ Sex } \\
\hline Girls & 1454 & (54.9) & 211 & (44.3) & \multirow[t]{2}{*}{$<0.001$} \\
\hline Boys & 1194 & (45.1) & 265 & (55.7) & \\
\hline \multicolumn{6}{|l|}{ Age (years) } \\
\hline$\leqslant 10$ & 1458 & (55.1) & 255 & $(53.6)$ & \multirow[t]{3}{*}{0.37} \\
\hline $11-12$ & 512 & (19.3) & 85 & (17.9) & \\
\hline$>12$ & 678 & (25.6) & 136 & (28.5) & \\
\hline \multicolumn{6}{|l|}{ Ethnicity } \\
\hline Non-Hispanic white & 1823 & $(68.8)$ & 338 & (71.0) & \multirow[t]{2}{*}{0.35} \\
\hline Hispanic white & 825 & (31.2) & 138 & $(29.0)$ & \\
\hline \multicolumn{6}{|c|}{ Parental history of asthma } \\
\hline No & 2075 & (83.1) & 265 & $(58.6)$ & \multirow[t]{2}{*}{$<0.001$} \\
\hline Yes & 422 & (16.9) & 187 & $(41.4)$ & \\
\hline \multicolumn{6}{|l|}{ Child's atopic status $\S$} \\
\hline No & 1687 & (68.3) & 131 & (31.2) & \multirow[t]{2}{*}{$<0.001$} \\
\hline Yes & 782 & $(31.7)$ & 289 & $(68.8)$ & \\
\hline \multicolumn{6}{|c|}{ In utero exposure to maternal smoking } \\
\hline No & 2149 & (83.0) & 380 & (80.7) & \multirow{2}{*}{0.23} \\
\hline Yes & 441 & (17.0) & 91 & (19.3) & \\
\hline \multicolumn{6}{|c|}{ Number of smokers at home } \\
\hline 0 & 1819 & (71.0) & 313 & (67.7) & \multirow[t]{3}{*}{0.26} \\
\hline 1 & 502 & (19.6) & 96 & $(20.8)$ & \\
\hline$\geqslant 2$ & 240 & (9.4) & 53 & (11.5) & \\
\hline \multicolumn{6}{|l|}{ Annual family income (\$) } \\
\hline$<15000$ & 317 & (13.9) & 49 & (11.7) & \multirow[t]{3}{*}{0.15} \\
\hline $15000-49999$ & 969 & (42.5) & 167 & (39.9) & \\
\hline$\geqslant 50000$ & 994 & $(43.6)$ & 207 & $(48.4)$ & \\
\hline \multicolumn{6}{|c|}{ Parent/quardian education } \\
\hline$<12$ th grade & 320 & (12.4) & 33 & (7.0) & \multirow[t]{5}{*}{0.005} \\
\hline 12th grade & 494 & (19.2) & 95 & (20.2) & \\
\hline Some college & 1160 & $(45.0)$ & 242 & (51.5) & \\
\hline College & 268 & (10.4) & 46 & (9.8) & \\
\hline Some graduate & 336 & (13.0) & 54 & (11.5) & \\
\hline \multicolumn{6}{|c|}{ Health insurance coverage } \\
\hline No & 400 & (15.3) & 37 & (7.9) & \multirow[t]{2}{*}{$<0.001$} \\
\hline Yes & 2208 & (84.7) & 430 & (92.1) & \\
\hline
\end{tabular}

*Participants include non-Hispanic and Hispanic white children of the Children's Health Study with and without asthma with available EPHXI Tyr1 13His and His 139Arg genotypes obtained from buccal samples collected during 1998-2006. †Totals differ due to missing data.

tp values from Pearson $\chi^{2}$ tests comparing children with asthma with those without asthma. $\S$ Child's atopic status was determined based on parental report of allergy and hay fever. 
phenotypes were combined (ie, low/intermediate) for testing the interaction between EPHXl phenotypes and GSTPI Ile105Val and distance of residence from major roads. For GSTP1 Ile105Val we used a co-dominant coding for testing the interactions. We have previously observed that children living within 75 metres of a major road were at a higher risk of asthma. ${ }^{1}$ We therefore examined whether the relationship between EPHXI phenotypes and asthma differed in children living $<75$ metres and $\geqslant 75$ metres from a major road. All tests were two-sided at a 5\% significance level. SAS V.9.1 (SAS Institute Inc, Cary, North Carolina, USA) was used for all analyses.

\section{RESULTS}

Compared with children with no asthma, children with physician-diagnosed asthma were more likely to be male (asthma prevalence $18.2 \%$ in boys, $12.7 \%$ in girls; $\mathrm{p}<0.0001$ ), to have a parental history of asthma $(\mathrm{p}<0.0001)$ and to have health insurance coverage $(\mathrm{p}<0.0001)$ (table 1$)$. Children with atopy were at an increased risk of asthma $(p<0.0001)$; however, EPHXI and GSTPl genotypes and EPHXl phenotypes were not associated with atopy (all $\mathrm{p}>0.20$ ). Although children with and without asthma had significant differences in the distribution of parent/guardian education, they did not differ by year of cohort entry, age, ethnicity or annual family income. Children with early persistent asthma were more likely to be exposed to two or more smokers at home $(p=0.04)$ and to maternal smoking in utero $(\mathrm{p}=0.06)$ than children with no asthma diagnosis. The EPHX1 Tyrl13His and His139Arg and the GSTP1 Ilel05Val genotypes were in Hardy-Weinberg equilibrium in the overall cohort and in non-Hispanic and Hispanic white children without asthma (table E5 in the online supplement available at http://thorax.bmj.com/supplemental).

Although EPHXI Tyrl13His polymorphism was not significantly associated with lifetime asthma, statistically significant association was found for late onset asthma (table 2). Compared with children with the Tyr/Tyr genotype at the Tyr 113 His locus, those with the His/His genotype were $49 \%$ less likely to have late onset asthma (95\% CI 0.29 to 0.88). Children heterozygous for the $139 \mathrm{His}$ allele had significantly increased risk of lifetime, current and late onset asthma) than children with no 139His allele. The GSTP1 Ile105Val polymorphism was associated with asthma, and the association was stronger for children with early persistent asthma. Compared with children homozygous for the Ile allele, those with one and two Val alleles had a 1.37 (95\% CI 0.95 to 1.96 ) and 1.95 (95\% CI 1.19 to 3.18) times increased risk of early persistent asthma, respectively. Variants in GSTM1 and GSTT1 were not associated with asthma phenotypes in this sample (table E6 in the online supplement available at http://thorax.bmj.com/supplemental).

The EPHXl phenotypes and diplotypes were significantly associated with asthma (table 3 ). Children with the high EPHXl phenotype had a 1.51 times higher risk of lifetime asthma (95\% CI 1.14 to 1.98) than children with the low EPHXl phenotype, and a statistically significant trend of increasing asthma risk with higher EPHXl activity was observed $(p=0.007)$. The results were similar (not shown) when another genotype-derived EPHXl phenotype classification described by Smith and Harrison was used. ${ }^{20}$ In the combined sample the diplotype frequencies for 113His-139His (low-low), 113His-139Arg (low-high), 113Tyr-139His (highlow) and 113Tyr-139Arg (high-high) were 0.24, 0.07, 0.58 and 0.10 , respectively. The diplotype frequencies did not differ between non-Hispanic and Hispanic white children. Children with one copy of the 113Tyr-139Arg (high-high) diplotype were at 1.32 fold (95\% CI 1.04 to 1.67) increased risk of asthma compared with those with two copies of the 113His-139His (low-low) diplotypes. These associations were stronger in children with late onset asthma.

The association between EPHXI phenotypes and asthma varied by GSTP1 Ile105Val genotype (table 4). In children with GSTP1 105Val/Val genotypes, those with high EPHXI activity had a 4 -fold (95\% CI 1.97 to 8.16) increased risk of lifetime asthma compared with children with low/intermediate EPHXI activity phenotypes. High EPHXI activity was not statistically significantly associated with an increased risk of asthma in children with GSTP1 105 Ile/Ile or Ile/Val genotypes. The results were similar for early persistent, late onset and current asthma. The GSTMI and GSTT1 null/present genotype did not modify the relationship between EPHXland GSTP1 Ilel05Val and asthma (not shown).

The associations between EPHXl phenotypes and asthma depended on the proximity of a child's home to a major road (table 5). Among children who lived within 75 metres of a major road, those who had high EPHXl activity had a 3.24-fold (95\% CI 1.75 to 6.00 ) increased risk of lifetime asthma ( $p$ for interaction $=0.03)$ compared with children with low/intermediate EPHXl activity. High EPHXl activity was not

Table 2 Associations between the EPHX1 (Tyr113His and His139Arg) and GSTP1 (lle105Val) polymorphisms and asthma phenotypes

\begin{tabular}{|c|c|c|c|c|c|c|c|c|c|}
\hline & \multirow{2}{*}{$\frac{\text { No asthma }}{\mathrm{N}}$} & \multicolumn{2}{|c|}{ Lifetime asthma } & \multicolumn{2}{|c|}{ Current asthma } & \multicolumn{2}{|c|}{$\begin{array}{l}\text { Early persistent asthma } \\
\text { (diagnosis by } 3 \text { years) }\end{array}$} & \multicolumn{2}{|c|}{$\begin{array}{l}\text { Late onset asthma (diagnosis } \\
\text { after } 3 \text { years) }\end{array}$} \\
\hline & & $\mathrm{N}$ & $\mathrm{OR}^{*}(95 \% \mathrm{Cl})$ & $\mathrm{N}$ & $\mathrm{OR}^{*}(95 \% \mathrm{Cl})$ & $\mathrm{N}$ & $\mathrm{OR}^{*}(95 \% \mathrm{Cl})$ & $\mathrm{N}$ & $\mathrm{OR}^{*}(95 \% \mathrm{Cl})$ \\
\hline \multicolumn{10}{|c|}{ EPHX1 Tyrl13His } \\
\hline $\mathrm{Tyr} / \mathrm{Tyr}$ & 1253 & 241 & 1.0 & 154 & 1.0 & 89 & 1.0 & 126 & 1.0 \\
\hline Tyr/His & 1112 & 189 & 0.86 (0.69 to 1.07 ) & 124 & 0.87 (0.67 to 1.12 ) & 62 & 0.81 (0.57 to 1.15$)$ & 99 & 0.83 (0.62 to 1.10 ) \\
\hline $\mathrm{His} / \mathrm{His}$ & 283 & 46 & 0.79 (0.55 to 1.13$)$ & 30 & $0.79(0.51$ to 1.22$)$ & 24 & 1.21 (0.74 to 1.97$)$ & 16 & 0.51 (0.29 to 0.88 \\
\hline \multicolumn{10}{|c|}{ EPHXI His139Arg } \\
\hline $\mathrm{His} / \mathrm{His}$ & 1817 & 290 & 1.0 & 186 & 1.0 & 112 & 1.0 & 140 & 1.0 \\
\hline $\mathrm{His} / \mathrm{Arg}$ & 741 & 174 & $1.42(1.14$ to 1.76$)$ & 114 & 1.45 (1.12 to 1.89$)$ & 57 & 1.25 (0.89 to 1.78$)$ & 96 & 1.58 (1.19 to 2.10 \\
\hline $\mathrm{Arg} / \mathrm{Arg}$ & 90 & 12 & $0.78(0.41$ to 1.47$)$ & 8 & $0.81(0.38$ to 1.76$)$ & 6 & $0.94(0.38$ to 2.31$)$ & 5 & $0.68(0.26$ to 1.73$)$ \\
\hline \multicolumn{10}{|c|}{ GSTP1 lle105Val† } \\
\hline $\mathrm{lle} / \mathrm{Ile}$ & 1043 & 171 & 1.0 & 116 & 1.0 & 57 & 1.0 & 93 & 1.0 \\
\hline $\mathrm{lle} / \mathrm{Val}$ & 1229 & 230 & 1.17 (0.94 to 1.47$)$ & 146 & $1.08(0.82$ to 1.41$)$ & 85 & $1.37(0.95$ to 1.96$)$ & 116 & 1.08 (0.81 to 1.46$)$ \\
\hline $\mathrm{Val} / \mathrm{Val}$ & 343 & 65 & 1.31 (0.94 to 1.81$)$ & 38 & $1.14(0.76$ to 1.70$)$ & 29 & 1.95 (1.19 to 3.18$)$ & 26 & $0.93(0.58$ to 1.49$)$ \\
\hline
\end{tabular}

*ORs adjusted for age, sex, race/ethnicity, in utero exposure to maternal smoking, number of smokers at home, community of residence, parental education, health insurance and parental history of asthma.

†Data on GSTP1 Ile105Val genotype were unavailable for 43 children. 
Table 3 Associations between EPHX1 metabolic phenotypes, EPHX1 haplotypes and asthma phenotypes

\begin{tabular}{|c|c|c|c|c|c|c|c|c|c|}
\hline & \multirow{2}{*}{$\frac{\text { No asthma }}{\mathrm{N}}$} & \multicolumn{2}{|c|}{ Lifetime asthma } & \multicolumn{2}{|c|}{ Current asthma } & \multicolumn{2}{|c|}{$\begin{array}{l}\text { Early persistent asthma } \\
\text { (diagnosis by } 3 \text { years) }\end{array}$} & \multicolumn{2}{|c|}{$\begin{array}{l}\text { Late onset asthma (diagnosis } \\
\text { after } 3 \text { years) }\end{array}$} \\
\hline & & $\bar{N}$ & $\mathrm{OR}^{*}(95 \% \mathrm{Cl})$ & $\bar{N}$ & $\mathrm{OR}^{*}(95 \% \mathrm{Cl})$ & $\mathrm{N}$ & $\mathrm{OR}^{*}(95 \% \mathrm{Cl})$ & $\bar{N}$ & $\mathrm{OR}^{*}(95 \% \mathrm{Cl})$ \\
\hline \multicolumn{10}{|c|}{ EPHXI metabolic phenotypes $\uparrow$} \\
\hline Low & 1061 & 171 & 1.0 & 113 & 1.0 & 67 & 1.0 & 80 & 1.0 \\
\hline Intermediate & 1116 & 193 & $1.07(0.85$ to 1.35$)$ & 123 & $1.06(0.80$ to 1.41$)$ & 70 & 0.92 (0.64 to 1.33 ) & 98 & 1.21 (0.88 to 1.66$)$ \\
\hline High & 471 & 112 & 1.51 (1.14 to 1.98$)$ & 72 & 1.50 (1.08 to 2.09 ) & 38 & 1.28 (0.83 to 1.98$)$ & 63 & 1.84 (1.28 to 2.64$)$ \\
\hline $\mathrm{p}$ for trend & & & 0.007 & & 0.004 & & 0.38 & & 0.001 \\
\hline \multicolumn{10}{|l|}{ EPHXI diplotypesł } \\
\hline 113 His-139H His (low/low) & & & 1.0 & & 1.0 & & 1.0 & & 1.0 \\
\hline $113 \mathrm{Tyr}-139 \mathrm{H}$ is (fast/low) & & & $1.17(0.97$ to 1.41$)$ & & $1.19(0.95$ to 1.50$)$ & & 1.11 (0.84 to 1.47$)$ & & $1.26(0.97$ to 1.62$)$ \\
\hline $113 \mathrm{His}-139 \mathrm{Arg}$ (low/fast) & & & 1.42 (0.87 to 2.33 ) & & $1.61(0.91$ to 2.87$)$ & & 1.85 (0.94 to 3.65$)$ & & $1.09(0.53$ to 2.25$)$ \\
\hline 113 Tyr-139Arg (fast/fast) & & & 1.32 (1.04 to 1.67$)$ & & 1.33 (1.00 to 1.77$)$ & & 1.07 (0.73 to 1.55$)$ & & 1.61 (1.19 to 2.18$)$ \\
\hline
\end{tabular}

*ORs adjusted for age, sex, race/ethnicity, in utero exposure to maternal smoking, number of smokers at home, community of residence, parental education, health insurance and parental history of asthma.

†See table E2 in the online supplement (available at http://thorax.bmi.com/supplemental) for determinations of the EPHX1 phenotypes based on Tyr1 13His and His 139Arg polymorphisms. Low and fast within parentheses represent in vitro catalytic efficiency of the two EPHXI polymorphisms in the order the alleles are presented before the parentheses.

$\ddagger$ The ORs are per increase of one copy of the given diplotype.

statistically significantly associated with asthma risk in children who lived $\geqslant 75$ metres from a major road. To address the potential for exposure misclassification we restricted the analyses to children who were long-term residents at their home addresses (ie, lived $\geqslant 1$ years before asthma diagnosis or study entry) and found similar results (table E7 in the online supplement available at http://thorax.bmj.com/supplemental). In this restricted sample, among children living within 75 metres of a major road, those with high EPHXl activity had a 4.16-fold (95\% CI 1.84 to 9.42) increased risk of asthma ( $\mathrm{p}$ for interaction $=0.009$ ) compared with children with low/ intermediate EPHXl activity.

The association between EPHXI high activity phenotype and lifetime asthma varied by GSTP1 Ilel05Val and residential location near major roads ( $p$ for interaction $=0.04$, table 6 ). Children were at the highest risk if they had high EPHXl phenotype, GSTP1 105Val allele and lived near major roads. Children with high EPHXI activity and living within 75 metres of a major road had a 2.61-fold (95\% CI 1.22 to 5.58) and 8.91fold (95\% CI 2.40 to 33.12 ) increased risk of asthma if they had one and two GSTP1 105Val alleles, respectively, compared with children with low/intermediate EPHXl activity, GSTP1 Ile/Ile genotype who lived $\geqslant 75$ metres from a major road. The corresponding ORs in long term residents were 2.67 (95\% CI 1.06 to 6.73 ) and 5.50 (95\% CI 1.05 to 28.72 ), respectively (table E8 in the online supplement available at http://thorax.bmj.com/ supplemental). The results were essentially similar for current, early persistent and late onset asthma (not shown). However, the confidence limits were imprecise for early persistent and late onset asthma because of small sample sizes available for analysis.

Maternal smoking during pregnancy, exposure to second hand smoke, number of smokers at home, race/ethnicity, child's sex, child's atopic status and parental asthma did not modify any of the genetic associations (data not shown).

\section{DISCUSSION}

We found that a high EPHXI metabolic phenotype is associated with an increased occurrence of asthma in children. This association varied by GSTP1 Ilel05Val genotypes and by distance of residence from major roads. For early persistent asthma the increased risk associated with a high EPHXl phenotype was only found in children who also had the GSTP1 105Val allele or lived near major roads. When genes and environmental exposures were considered together, children with high EPHXl activity and the GSTP1 105Val allele who

Table 4 Association between EPHX1 phenotypes and asthma stratified by GSTP1 lle105Val genotype

\begin{tabular}{|c|c|c|c|c|c|c|c|}
\hline \multirow{3}{*}{$\begin{array}{l}\text { EPHX1 metabolic } \\
\text { phenotypes by asthma } \\
\text { phenotypes }\end{array}$} & \multicolumn{6}{|c|}{ GSTP1 lle 105Val } & \multirow[b]{3}{*}{ p Valuef } \\
\hline & \multicolumn{2}{|l|}{ lle/lle } & \multicolumn{2}{|l|}{ lle/Val } & \multicolumn{2}{|l|}{$\mathrm{Val} / \mathrm{Val}$} & \\
\hline & $\mathrm{N}^{*}$ & ORt $(95 \% \mathrm{Cl})$ & $\overline{\mathbf{N}^{*}}$ & ORt $(95 \% \mathrm{Cl})$ & $\mathrm{N}^{*}$ & OR† $(95 \% \mathrm{Cl})$ & \\
\hline \multicolumn{8}{|l|}{ Lifetime asthma } \\
\hline Low/intermediate & $842 / 135$ & 1.0 & $1012 / 181$ & 1.0 & $297 / 42$ & 1.0 & \\
\hline High & $201 / 36$ & 1.12 (0.74 to 1.70$)$ & $217 / 49$ & 1.34 (0.92 to 1.94$)$ & $46 / 23$ & 4.01 (1.97 to 8.16$)$ & 0.006 \\
\hline \multicolumn{8}{|l|}{ Current asthma } \\
\hline Low/intermediate & $842 / 94$ & 1.0 & $1012 / 114$ & 1.0 & $297 / 24$ & 1.0 & \\
\hline High & $201 / 22$ & 1.15 (0.67 to 2.00$)$ & $217 / 32$ & $1.31(0.80$ to 2.13$)$ & $46 / 14$ & 4.42 (1.65 to 11.83$)$ & 0.03 \\
\hline \multicolumn{8}{|l|}{ Early persistent asthma } \\
\hline Low/intermediate & $842 / 49$ & 1.0 & $1012 / 66$ & 1.0 & $297 / 19$ & 1.0 & \\
\hline High & $201 / 8$ & 0.65 (0.29 to 1.43 ) & $217 / 19$ & 1.55 (0.87 to 2.76$)$ & $46 / 10$ & 3.89 (1.32 to 11.43 ) & 0.02 \\
\hline \multicolumn{8}{|l|}{ Late onset asthma } \\
\hline Low/intermediate & $842 / 67$ & 1.0 & $1012 / 92$ & 1.0 & $297 / 16$ & 1.0 & \\
\hline High & $201 / 26$ & 1.65 (0.99 to 2.75$)$ & $217 / 24$ & 1.28 (0.78 to 2.11$)$ & $46 / 10$ & 4.40 (1.56 to 12.45$)$ & 0.06 \\
\hline
\end{tabular}

*Frequencies represent children with no asthma/children with asthma phenotype under study. Children with missing data on GSTP1 lle105Val were excluded. †ORs represent odds ratios for asthma outcomes associated with high EPHXI phenotype within each stratum of GSTP1 lle 105Val genotype and were adjusted for age, sex, race/ethnicity, in utero exposure to maternal smoking, number of smokers at home, community of residence, parental education, health insurance and parental history of asthma.

łp values for the EPHXI activity phenotype by GSTP1 lle105Val genotype interactions were obtained from likelihood ratio tests from a non-stratified model with appropriate interaction terms and were based on $2 \mathrm{df}$. 
Table 5 Association between EPHX1 phenotypes and asthma stratified by distance of residence from major roads

\begin{tabular}{|c|c|c|c|c|c|}
\hline \multirow{3}{*}{$\begin{array}{l}\text { EPHX1 metabolic } \\
\text { phenotypes by asthma } \\
\text { phenotypes }\end{array}$} & \multicolumn{4}{|c|}{ Distance of residence from a major road } & \multirow[b]{3}{*}{ p Valueł } \\
\hline & \multicolumn{2}{|l|}{$\geqslant 75$ metres } & \multicolumn{2}{|c|}{$<75$ metres } & \\
\hline & $\overline{\mathbf{N}^{*}}$ & ORt $(95 \% \mathrm{Cl})$ & $\overline{\mathrm{N}^{*}}$ & OR† $(95 \% \mathrm{Cl})$ & \\
\hline \multicolumn{6}{|l|}{ Lifetime asthma } \\
\hline Low/intermediate & $1540 / 261$ & 1.0 & $367 / 62$ & & \\
\hline High & $343 / 72$ & $1.25(0.93$ to 1.69$)$ & $66 / 27$ & 3.24 (1.75 to 6.00$)$ & 0.03 \\
\hline \multicolumn{6}{|l|}{ Current asthma } \\
\hline Low/intermediate & $1540 / 175$ & 1.0 & $367 / 37$ & 1.0 & \\
\hline High & $343 / 48$ & $1.34(0.91$ to 1.96$)$ & $66 / 16$ & 2.91 (1.25 to 6.77$)$ & 0.08 \\
\hline \multicolumn{6}{|l|}{ Early persistent asthma } \\
\hline Low/intermediate & $1540 / 99$ & 1.0 & $367 / 22$ & & \\
\hline High & $343 / 23$ & $1.10(0.67$ to 1.79$)$ & $66 / 9$ & 3.02 (1.09 to 8.33$)$ & 0.18 \\
\hline \multicolumn{6}{|l|}{ Late onset asthma } \\
\hline Low/intermediate & $1540 / 129$ & 1.0 & $367 / 30$ & & \\
\hline High & $343 / 41$ & $1.44(0.98$ to 2.11$)$ & $66 / 17$ & $4.85(2.22$ to 10.61$)$ & 0.02 \\
\hline \multicolumn{6}{|c|}{$\begin{array}{l}\text { *Frequencies represent children with no asthma/children with asthma phenotype under study. Children with missing data } \\
\text { on distance of residence from major road were excluded. } \\
\text { †ORs represent odds ratios for asthma outcomes associated with high EPHX1 phenotype within each stratum of } \\
\text { residential distance from major road and were adjusted for age, sex, race/ethnicity, in utero exposure to maternal } \\
\text { smoking, number of smokers at home, community of residence, parental education, health insurance and parental } \\
\text { history of asthma. } \\
\text { tp value for the EPHXI metabolic phenotypes by distance of residence from major road interactions were obtained from } \\
\text { likelihood ratio tests from a non-stratified model with appropriate interaction terms and was based on } 1 \mathrm{df} \text {. }\end{array}$} \\
\hline
\end{tabular}

lived within 75 metres of a major road were at the highest risk of asthma irrespective of age at asthma diagnosis.

Several lines of evidence support a role for variants in EPHXI, GSTPl and traffic in the pathogenesis of asthma. The first is the role of EPHXl in xenobiotic metabolism that is relevant to asthma. After EPHXI metabolises PAHs to trans-dihydrodiols, PAH trans-dihydrodiols can be further metabolised in at least two pathways. In one pathway, trans-dihydrodiols are metabolised to diol-epoxides which lead to electrophilic DNA adduct formation. This mechanism has been proposed as one underlying pathway for tissue damage and chronic health effects. ${ }^{16}$ In the second pathway, trans-dihydrodiols are metabolised to catechols by dihydrodiol dehydrogenase, the latter belonging to aldo-keto reductase family 1 (AKRls). ${ }^{16}$ Subsequently, autoxidation of catechol leads to generation of PAH 0 -quinones and superoxide anion, both of which have been shown to be cytotoxic and immunotoxic. In addition, PAH $o$-quinones can enter into futile redox cycling, ${ }^{29}$ thereby generating ROS. It is plausible that high EPHXl activity producing excessive catechols could overwhelm the conjugation processes. In addition, GSTP1 105Val allele mediated reduced conjugation of some of the PAH metabolites and increased oxidant stress ${ }^{8}$ could lead to inflammation and ROS mediated damage to the airways, resulting in increased asthma in children. Further research into the role of PAHs in asthma should consider functional variants in the AKRls in addition to those of EPHXI and GSTPl genes.

Although exposure to maternal smoking in utero and second hand smoke are sources of PAH exposures and were associated with early persistent asthma in this sample, these exposures did not affect the associations between EPHXl phenotypes and asthma. In an earlier study of participants in the Children's

Table 6 Joint effects of distance of residence from major road, EPHXI metabolic phenotypes and GSTP1 lle 105Val on lifetime asthma $(\mathrm{N}=2702)$

\begin{tabular}{|c|c|c|c|c|c|}
\hline $\begin{array}{l}\text { Distance of } \\
\text { residence from } \\
\text { major road } \\
\text { (metres) }\end{array}$ & $\begin{array}{l}\text { GSTP1 } \\
\text { lle105Val }\end{array}$ & $\begin{array}{l}\text { EPHX1 metabolic } \\
\text { phenotypes }\end{array}$ & $\begin{array}{l}\text { No } \\
\text { asthma } \\
\left(\mathrm{N}^{*}\right)\end{array}$ & $\begin{array}{l}\text { Lifetime } \\
\text { asthma } \\
\left(\mathrm{N}^{*}\right)\end{array}$ & OR† (95\% Cl) \\
\hline$\geqslant 75$ & $\mathrm{le} / \mathrm{lle}$ & Low/intermediate & 589 & 94 & 1.0 \\
\hline$\geqslant 75$ & $\mathrm{lle} / \mathrm{Val}$ & Low/intermediate & 720 & 132 & $1.19(0.88$ to 1.61$)$ \\
\hline$\geqslant 75$ & $\mathrm{Val} / \mathrm{Val}$ & Low/intermediate & 215 & 29 & $0.94(0.59$ to 1.50$)$ \\
\hline$\geqslant 75$ & $\mathrm{lle} / \mathrm{lle}$ & High & 141 & 23 & $1.03(0.61$ to 1.71$)$ \\
\hline$\geqslant 75$ & $\mathrm{lle} / \mathrm{Val}$ & High & 158 & 31 & $1.35(0.85$ to 2.15$)$ \\
\hline$\geqslant 75$ & $\mathrm{Val} / \mathrm{Val}$ & High & 38 & 14 & $2.63(1.34$ to 5.18$)$ \\
\hline$<75$ & $\mathrm{lle} / \mathrm{lle}$ & Low/intermediate & 144 & 23 & $1.01(0.60$ to 1.69$)$ \\
\hline$<75$ & $\mathrm{lle} / \mathrm{Val}$ & Low/intermediate & 171 & 28 & $0.89(0.54$ to 1.44$)$ \\
\hline$<75$ & $\mathrm{Val} / \mathrm{Val}$ & Low/intermediate & 48 & 11 & $1.46(0.71$ to 3.03$)$ \\
\hline$<75$ & $\mathrm{lle} / \mathrm{lle}$ & High & 31 & 9 & $1.71(0.75$ to 3.87$)$ \\
\hline$<75$ & $\mathrm{lle} / \mathrm{Val}$ & High & 30 & 12 & 2.61 (1.22 to 5.58$)$ \\
\hline$<75$ & $\mathrm{Val} / \mathrm{Val}$ & High & 5 & 6 & $\begin{array}{l}8.91(2.40 \text { to } 33.12) \\
p=0.04 \ddagger\end{array}$ \\
\hline
\end{tabular}

*Children with missing data on distance of residence from major road and GSTP1 lle105Val were excluded. †ORs adjusted for age, sex, race/ethnicity, in utero exposure to maternal smoking, number of smokers at home, community of residence, parental education, health insurance and parental history of asthma.

Ғp value for EPHX1 activity phenotype by distance of residence from a major road and by GSTP1 Ile105Val genotype interaction was obtained from likelihood ratio test from a non-stratified model with appropriate interaction terms and was based on $7 \mathrm{df}$. 
Health Study, exposure to in utero smoking was associated with asthma and wheeze in children who had the GSTM1 null genotype. ${ }^{5}$ Possible explanations for not finding a differential asthma risk with EPHXI activity in children with and without smoking exposures could be that the tobacco smoke contains exposures other than PAHs which are detoxified by other metabolic pathways. For instance, nicotine is a key tobacco component that has been associated with asthma. ${ }^{30}{ }^{31}$ However, EPHXl is not involved in nicotine metabolism ${ }^{32}$ and we have not considered nicotine metabolising genes such as cytochrome P450 (CYP2A6) or flavin-containing mono-oxygenase 3 (FMO3) in the current investigation. Further studies should consider functional variants in genes in $\mathrm{PAH}$ and nicotine metabolism pathways together to identify the genetically susceptible group of children who are at higher risk of asthma from tobacco smoke. We acknowledge that other exposures (eg, particle number concentrations and other particulate constituents such as transition metals) could be correlated with proximity of residence to major roads. However, given the observed associations between the genes involved in $\mathrm{PAH}$ metabolism (EPHXI and GSTP1) and asthma that varied with distance of residence from major roads, it is possible that differences in the distance of residence from major roads represented differential PAH exposure from traffic. Further research is needed to examine this hypothesis.

GSTPI Ile105Val polymorphism was associated with asthma and also modified the effect of EPHXI phenotypes on asthma. Although the ORs for GSTP1 Ilel05Val and EPHXI phenotypes were stronger in children with the GSTMI null genotype (not shown), GSTMI and GSTTl null genotypes were not independently associated with asthma. GSTPl is the predominant enzyme that contributes to the GST enzyme activity in the lungs. ${ }^{33}$ This may explain why significant associations were not found between GSTMl and GSTTl genotypes and asthma. Furthermore, GSTP1 Ile105Val was associated with early onset asthma but not with late onset asthma, which suggests age related pleiotropy in the effects of GSTP1 Ilel05Val genotype on asthma. This differential effect of GSTP1 Ilel05Val on age at onset asthma phenotype could explain the observed inconsistencies across studies in the association between GSTPl Ile105Val and asthma. ${ }^{9-14}$

We found that children with high EPHXl metabolic phenotype who lived near a major road were at a higher risk of asthma when they carried the variant Val allele in the GSTP1 105 locus. In this population, approximately 19\% of children had the high EPHXl phenotypes and $60 \%$ of children had the GSTP1 105 Ile/Val (47\%) or Val/Val (13\%) genotypes. About $70 \%$ of children carried one of these genetic susceptibility factors and about $20 \%$ lived within 75 metres of a major road. The percentage of children living near a major road did not vary by the genetic susceptibility factors. Taken together, these data suggest that a considerable proportion of children (approximately 13\%) in southern California with functional variants in $\mathrm{PAH}$ metabolising genes are at a higher risk of asthma from local traffic related pollution.

The strengths of the present study include selection of SNPs with well documented functional significance, large sample sizes where children without asthma were in Hardy-Weinberg equilibrium for each genotype, use of allelic discrimination assay rather than using restriction fragment length polymorphism (RFLP) method that reduced genotype misclassifications, ${ }^{34}$ consistent findings in genotype, diplotype and phenotype-based analyses, all main and joint effects in the same directions by race justifying a combined analysis, and biological plausibility for the observed associations.

One concern regarding this study involves the use of physician-diagnosed asthma for our case definition. To address this problem we independently validated asthma diagnosis in a subset of the Children's Health Study cohort. In a case-control study $^{35}$ nested in the Children's Health Study, 221 parents provided consent and at least partial information on the physician who made the asthma diagnosis. We were able to obtain medical records of 172 children with asthma and $95.9 \%$ of them $(n=165)$ had either a definite (physician diagnosis of asthma, $\mathrm{n}=118$ ) or a probable (physician report of wheeze and steroid and/or $\beta_{2}$ adrenergic agonist use, $n=54$ ) asthma diagnosis. Restricting the analysis to definite and probable asthma showed similar associations to those found in the overall sample.

Children who provided buccal samples differed in socioeconomic and demographic factors from those who did not participate in the study, and the proportion of Hispanic white children varied by community (tables E9 and E10 in the online supplement available at http://thorax.bmj.com/supplemental). To assess the potential for selection bias we adjusted all analyses for socioeconomic and demographic factors and found relatively little impact of these factors on the associations. To detect any influence of any particular community on the associations observed, we excluded data from one community at a time and repeated the analysis. These sensitivity analyses did not show any particular influence of any single community. We also restricted the analyses to children with health insurance and observed similar results (not shown). In light of these observations, it is less likely that subject recruitment and demographic variations by community could explain the findings. Although we had sufficient power to detect the ORs found, caution should be used in interpreting some of the results which are based on smaller sample sizes.

We decided to conduct the study using personal level traffic data that represented within-community differences in exposure levels and to follow a pathway-based approach for the gene selection; this meant that fewer statistical tests were conducted. Besides, the functional significance of the EPHXI phenotypes and GSTP1 Ilel05Val genotypes have been documented and the analyses were based on specified a priori hypotheses. In this setting it may not be appropriate to disregard prior information on the functional significance of the genetic variants under study and to adjust the $\mathrm{p}$ values for testing a set of selected a priori hypotheses.

We conclude that high EPHXl metabolic activity and the GSTP1 105Val genotype are associated with asthma in children, and the risk is higher in this genetically susceptible group of children who live near major roads. Based on these findings, we hypothesise that specific PAH mediated generation of $o$ quinones and ROS could be a pathway for the pathogenesis of asthma in childhood. Further research is needed to consider specific $\mathrm{PAH}$ exposures and genes in the $\mathrm{PAH}$ metabolic pathway in childhood asthma.

\section{ACKNOWLEDGEMENTS}

The authors acknowledge the efforts of the study field team and the participation of the 12 communities, the school principals, the many teachers, the students and their parents. The authors thank Jun Manila, Ed Rappaport and Madé Wenten for database management.

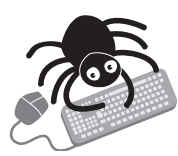

Further details are given in the online supplement available at http://thorax.bmj.com/supplemental

\section{Authors' affiliations \\ Muhammad T Salam, Pi-Chu Lin, Edward L Avol, W James Gauderman, \\ Frank D Gilliland, Department of Preventive Medicine, University of} Southern California Keck School of Medicine, Los Angeles, California, USA 
This study was supported by the National Institute of Environmental Health Sciences (grants 5P01 ES09581, 5P01ES01 1627 and 5P30 ES07048), the US Environmental Protection Agency (grants R826708-01 and RD83186101), the National Heart, Lung, and Blood Institute (grants 5R01HL61768 and 5R01HL076647), the California Air Resources Board (contract 94-331) and the Hastings Foundation. The study sponsors had no role in the study design, in the collection, analysis and interpretation of data, in the writing of the report or in the decision to submit the paper for publication.

Competing interests: None.

\section{REFERENCES}

1 McConnell R, Berhane K, Yao L, et al. Traffic, susceptibility, and childhood asthma. Environ Health Perspect 2006; 114:766-72.

2 Gauderman WJ, Avol E, Lurmann F, et al. Childhood asthma and exposure to traffic and nitrogen dioxide. Epidemiology 2005;16:737-43.

3 Gauderman WJ, Vora H, McConnell R, et al. Effect of exposure to traffic on lung development from 10 to 18 years of age: a cohort study. Lancet 2007;369:571-7.

4 Gilliland FD, Li YF, Peters JM. Effects of maternal smoking during pregnancy and environmental tobacco smoke on asthma and wheezing in children. Am J Respir Crit Care Med 2001; 163:429-36

5 Gilliland FD, Li YF, Dubeau L, et al. Effects of glutathione S-transferase MI, maternal smoking during pregnancy, and environmental tobacco smoke on asthma and wheezing in children. Am J Respir Crit Care Med 2002; 166:457-63.

6 Jedrychowski W, Galas A, Pac A, et al. Prenatal ambient air exposure to polycyclic aromatic hydrocarbons and the occurrence of respiratory symptoms over the first year of life. Eur J Epidemiol 2005;20:775-82.

7 Miller RL, Garfinkel R, Horton M, et al. Polycyclic aromatic hydrocarbons, environmental tobacco smoke, and respiratory symptoms in an inner-city birth cohort. Chest 2004;126:1071-8.

8 Ercan H, Birben E, Dizdar EA, et al. Oxidative stress and genetic and epidemiologic determinants of oxidant injury in childhood asthma. J Allergy Clin Immunol 2006;118:1097-104.

9 Fryer AA, Bianco A, Hepple M, et al. Polymorphism at the glutathione Stransferase GSTP1 locus. A new marker for bronchial hyperresponsiveness and asthma. Am J Respir Crit Care Med 2000;161:1437-42.

10 Hemmingsen A, Fryer AA, Hepple $M$, et al. Simultaneous identification of GSTP1 Ile105-->Val105 and Ala1 14-->Val114 substitutions using an amplification refractory mutation system polymerase chain reaction assay: studies in patients with asthma. Respir Res 2001;2:255-60.

11 Aynacioglu AS, Nacak M, Filiz A, et al. Protective role of glutathione Stransferase P1 (GSTP1) Val105Val genotype in patients with bronchial asthma. Br J Clin Pharmacol 2004;57:213-7.

12 Tamer L, Calikoglu M, Ates NA, et al. Glutathione-S-transferase gene polymorphisms (GSTT1, GSTM1, GSTP1) as increased risk factors for asthma. Respirology 2004;9:493-8.

13 Nickel R, Haider A, Sengler C, et al. Association study of Glutathione Stransferase P1 (GSTP1) with asthma and bronchial hyper-responsiveness in two German pediatric populations. Pediatr Allergy Immunol 2005; 16:539-41.

14 Brasch-Andersen C, Christiansen L, Tan Q, et al. Possible gene dosage effect of glutathione-S-transferases on atopic asthma: using real-time PCR for quantification of GSTM1 and GSTT1 gene copy numbers. Hum Mutat 2004;24:208-14.

15 Lee YL, Hsive TR, Lee YC, et al. The association between glutathione S-transferase P1 , M1 polymorphisms and asthma in Taiwanese schoolchildren. Chest 2005;128: 1156-62.
16 Bolton JL, Trush MA, Penning TM, et al. Role of quinones in toxicology. Chem Res Toxicol 2000; 13:135-60.

17 Hassett C, Aicher L, Sidhu JS, et al. Human microsomal epoxide hydrolase: genetic polymorphism and functional expression in vitro of amino acid variants. Hum Mol Genet 1994;3:421-8.

18 Hosagrahara VP, Rettie AE, Hassett C, et al. Functional analysis of human microsomal epoxide hydrolase genetic variants. Chem Biol Interact 2004;150:149-59.

19 Benhamou S, Reinikainen M, Bouchardy C, et al. Association between lung cancer and microsomal epoxide hydrolase genotypes. Cancer Res 1998:58:5291-3.

20 Smith CA, Harrison DJ. Association between polymorphism in gene for microsomal epoxide hydrolase and susceptibility to emphysema. Lancet 1997;350:630-3.

21 Suzuki T, Coggan M, Shaw DC, et al. Electrophoretic and immunological analysis of human glutathione S-transferase isozymes. Ann Hum Genet 1987;51:95-106.

22 Pemble S, Schroeder KR, Spencer SR, et al. Human glutathione S-transferase theta (GSTT1): CDNA cloning and the characterization of a genetic polymorphism. Biochem J 1994;300(Pt 1):271-6.

23 Hu X, Xia H, Srivastava SK, et al. Catalytic efficiencies of allelic variants of human glutathione S-transferase $\mathrm{P} 1-1$ toward carcinogenic anti-diol epoxides of benzo[c]phenanthrene and benzo[g]chrysene. Cancer Research 1998;58:5340-3.

24 Cheng SL, Yu CJ, Chen CJ, et al. Genetic polymorphism of epoxide hydrolase and glutathione S-transferase in COPD. Eur Respir J 2004;23:818-24.

25 Peters JM, Avol E, Gauderman WJ, et al. A study of twelve Southern California communities with differing levels and types of air pollution. II. Effects on pulmonary function. Am J Respir Crit Care Med 1999;159:768-75.

26 Peters JM, Avol E, Navidi W, et al. A study of twelve Southern California communities with differing levels and types of air pollution. I. Prevalence of respiratory morbidity. Am J Respir Crit Care Med 1999;159:760-7.

27 Stram DO, Haiman CA, Hirschhorn JN, et al. Choosing haplotype-tagging SNPS based on unphased genotype data using a preliminary sample of unrelated subjects with an example from the Multiethnic Cohort Study. Hum Hered 2003;55:27-36.

28 Martinez FD, Wright AL, Taussig $L M$, et al. Asthma and wheezing in the first six years of life. The Group Health Medical Associates. N Engl J Med 1995;332:133-8.

29 Jiang $\mathrm{H}$, Vudathala DK, Blair IA, et al. Competing roles of aldo-keto reductase $1 \mathrm{~A} 1$ and cytochrome P4501B1 in benzo[a]pyrene-7,8-diol activation in human bronchoalveolar H358 cells: role of AKRs in P4501B1 induction. Chem Res Toxicol 2006; 19:68-78

30 Eisner MD, Klein J, Hammond SK, et al. Directly measured second hand smoke exposure and asthma health outcomes. Thorax 2005;60:814-21.

31 Schuller HM, Jull BA, Sheppard BJ, et al. Interaction of tobacco-specific toxicants with the neuronal alpha(7) nicotinic acetylcholine receptor and its associated mitogenic signal transduction pathway: potential role in lung carcinogenesis and pediatric lung disorders. Eur J Pharmacol 2000;393:265-77.

32 Hukkanen J, Jacob P 3rd, Benowitz NL. Metabolism and disposition kinetics of nicotine. Pharmacol Rev 2005;57:79-115.

33 Baver $M$, Herbarth $O$, Aust $G$, et al. Expression patterns and novel splicing variants of glutathione-S-transferase isoenzymes of human lung and hepatocyte cell lines. Cell Tissue Res 2006;324:423-32.

34 Gsur A, Zidek T, Schnattinger K, et al. Association of microsomal epoxide hydrolase polymorphisms and lung cancer risk. Br J Cancer 2003;89:702-6.

35 Salam MT, Li YF, Langholz B, et al. Early-life environmental risk factors for asthma: findings from the Children's Health Study. Environ Health Perspect 2004; 112:760-5.

\section{Save your favourite articles and useful searches}

Use the "My folders" feature to save and organise articles you want to return to quickly-saving space on your hard drive. You can also save searches, which will save you time. You will only need to register once for this service, which can be used for this journal or all BMJ Journals, including the BMJ. 